\title{
WHEEL BALANCING MACHINE DESIGN
}

\author{
Emin Yilmaz \\ Department of Technology \\ University of Maryland Eastern Shore \\ Princess Anne, MD 21853
}

\begin{abstract}
The goal of the Wheel Balancing Machine Design project was to introduce students to designing mechanical systems in the ETME475-Mechanical Systems Design course. Project was completed in stages as a laboratory requirement for the course. The machine consists of a frame, an electric motor, a belt driven shaft on two spherical bearings, an anchoring system to attach the wheel to the shaft, and associated instrumentation. Instrumentation is used to: (a) measure the amount of the force caused by the non-uniform distribution of wheel mass, (b) convert it to an equivalent counterweight mass to be placed on the wheel rim to balance the wheel, and (c) find the angular position on the rim where the mass needs to be placed. A shaft encoder is used to measure the angular position and an accelerometer is used to measure the angular acceleration due to unbalance force on the wheel. A PC based data acquisition system with ASYST software was used for data acquisition, analysis and display.

Due to some mechanical and instrumentation related technical difficulties, this fairly complicated class project turned out to be an applied research project. These technical problems were dealt one at a time.
\end{abstract}

\section{NOMENCLATURE}

A $=$ total amplification of accelerometer signal

$\mathrm{I}=$ moment of inertia

$\mathrm{K}$ = calibration constant for a balanced wheel of rim size $\mathrm{R}$.

$\mathrm{M}=$ maximum moment along the shaft

$\mathrm{R}=$ rim radius at which mass " $\mathrm{m}$ " is placed

$\mathrm{S}=$ sensitivity of accelerometer (usually in $\mathrm{mV} / \mathrm{g}$ )

$\mathrm{W}=$ Total weight of the system

$\mathrm{a}=$ measured acceleration

c $=$ half height of the cross section

$\mathrm{g}=$ standard gravitational acceleration

$\mathrm{m}=$ counterbalance mass

$\omega=$ angular velocity of wheel 


\section{INTRODUCTION}

Students in the Mechanical Engineering Technology program are required to take at least one Systems Design course during the last year of their program. As part of the requirement for this course, students are assigned to design a system or systems that require use of the knowledge that they have acquired in lower level courses. Sometimes they are assigned a group project if the project is large enough.

The Wheel Balancing Machine design project was assigned, during spring semester of 1991, to one student. He finished most of the mechanical design but did not return back after spring break to work on manufacturing. The project was assigned to another student, in spring semester of 1993, to complete the manufacturing of the project. When the first student returned to school in fall semester of 1995, I worked with him on the instrumentation of the Wheel Balancing machine and writing a data acquisition program using LabTech/CONTROL[1] software. Third student modified the instrumentation during the spring semester of 1997. Since data acquisition by LabTech/CONTROL was not fast, we used ASYST[2] software for data acquisition, analysis and display. During the Spring semester of 1998, fourth student worked on the project to remanufacture the shaft and the wheel anchoring system to closer tolerances to improve the accuracy of measurements.

The purpose of this paper is to describe the wheel-balancing machine and convey the experiences we had during the design and construction of the wheel-balancing machine.

\section{MECHANICAL DESIGN OF THE WHEEL BALANCING MACHINE}

Dynamic balancing of a wheel requires that the wheel be in rotational motion. Rotational motion is accomplished by a $1750 \mathrm{rpm}, 1 / 2 \mathrm{hp}$ electric motor. Motor speed is reduced to 600 -rpm shaft speed by a belt and pulley system attached to one end of the shaft. The wheel is attached to the other side of the shaft by using a back cone mounting system consisting of a faceplate, a spring, a metal cone, a pressure cup and a nut. The metal cone and the spring helps to center the wheel, while the face plate, and the cup insures that the wheel is perpendicular to the shaft as the nut is tightened. The faceplate was welded to the shaft on the original system. In the new design, the faceplate shall be pressure fitted to the shaft to prevent welding distortions in the shaft. A four-legged metal frame, made of 1.5-inch equal leg iron angles, supports the bearings and the electric motor. The shaft is supported by two one-inch diameter pillow block spherical ball bearings. A 72-hole, photo interrupter Plexiglas disk and a rotational encoder is attached to the pulley-end of the shaft for triggering and angular position measurements. Electric motor is supported by vibration isolation mounts on the two angles at the bottom of the frame. A 0.4-inch size V-belt runs from 1.5 diameter motor pulley to 4.5 -inch diameter shaft pulley. The spring has a 4 -inch free length, 1/8inch wire diameter and $24 \mathrm{lb} /$ in spring constant. Some drawings of the mechanical system are given in Fig.1 and Fig.2. Photo of whole system is given in Fig.3.

One-inch shaft diameter was calculated using

$$
\mathrm{s}=\mathrm{M} * \mathrm{c} / \mathrm{I}
$$


with a safety factor of 5 and a yield stress of $36 \mathrm{ksi}$ for cold rolled steel. Selection of $0.25 \times 1.5 \times 1.5$ inch iron angles for the frame was based on experience for proper rigidity. Compressive stresses in the legs due to wheel weight and the dynamic forces were checked and were found to be very small. Torsional stress in the one-inch diameter shaft during acceleration is negligible.

\section{WHEEL BALANCING MACHINE INSTRUMENTATION}

\section{(a). Measurement of the Unbalance Force}

An accelerometer attached to the frame of the machine is used to indirectly measure acceleration due to unbalance in the tire as tire rotates at about $600 \mathrm{rpm}$. Accelerometer output signal can be related to the counterbalance mass to be placed at the rim radius by [3]:

$$
\mathrm{m}=(\mathrm{a} * \mathrm{~W} / \mathrm{g}) /\left(\omega^{2} * \mathrm{R}\right)
$$

Accelerometer output voltage can be found by:

$$
\mathrm{V}=\mathrm{A} * \mathrm{~S} * \mathrm{a}
$$

Using Eq. (3) in Eq. (2) one obtains:

$$
\mathrm{m}=(\mathrm{V} * \mathrm{~W} / \mathrm{g}) /\left(\mathrm{A} * \mathrm{~S} * \omega^{2} * \mathrm{R}\right)
$$

As seen in Eq. (4), since "W", "g", "A", "S" and " $\omega$ " are constants, " $m$ " is directly proportional to "V" and inversely proportional to "R". Therefore, one can calibrate the system by measuring the output voltage signal due to known unbalance masses at the rims of different sizes of balanced wheels. Thus, the balancing mass to be placed on the rim can be calculated by:

$$
\mathrm{m}=\mathrm{K} * \mathrm{~V}
$$

Technical specifications for the PCB[4] accelerometer used for the wheel-balancing machine are given in Table 1.

For a 14 inch wheel, Eq. (4) gives a calculated sensitivity of $1.44 \mathrm{~V} / \mathrm{oz}$ for our system $(\mathrm{R}=7.5 \mathrm{in}$, $\mathrm{W}=150 \mathrm{lbs}$., $\mathrm{N}=593.5 \mathrm{rpm}, \omega=62.15 \mathrm{rad} / \mathrm{s}, \mathrm{S}=461 \mathrm{mV} / \mathrm{g}, \mathrm{A}=100$ ). Since commercial wheel balancing machines are sensitive to about $0.25 \mathrm{oz}$, our system should be capable of detecting $360 \mathrm{mV}(=1440 \mathrm{mV} / \mathrm{oz} * 0.25 \mathrm{oz})$ output or an acceleration of about $0.008 \mathrm{~g}$ $[360 \mathrm{mV} /(461 \mathrm{mV} / \mathrm{g}) / 100=0.00781 \mathrm{~g}]$ to match the sensitivity of the commercial machines. Table 1 indicates that we have $20(=0.008 / 0.0004)$ times more sensitive transducer. Actual measured sensitivity is $1.25 \mathrm{~V} / \mathrm{oz}$.

An active filter is used to filter the noise. The active filter was designed using Burr-Brown[5] UAF42 integrated filter/amplifier circuit. First operational amplifier in the filter circuit is configured to amplify the signal 10 times. 
Table 1. Technical Specifications for PCB Accelerometer

$\begin{array}{ll}============================ \\ \text { Model No } & : \text { U353B52 } \\ \text { Sensitivity } & : 461 \mathrm{mV} / \mathrm{g} \\ \text { Natural frequency } & : 16.5 \mathrm{kHz} \\ \text { Range } & : 10 \mathrm{~g} \\ \text { Resolution } & : 0.0004 \mathrm{~g} \\ \text { Frequency Response } & : 10 \mathrm{~Hz}-1 \mathrm{kHz} \sim \text { flat }\end{array}$

\section{(b). Angular Position Measurement}

A brush type binary encoder attached to the shaft is used to measure the location of the unbalance force in the wheel. The Locheed Martin Librascope[6] model 713-20-7 digital position encoder is of V-Scan type. V-Scan is an encoder interpolation method. The term V-Scan is derived from the geometric placement of the sensors which resembles a "V". The encoder consists of two sensors per bit. The least significant bit has only one sensor. To prevent ambiguity in decoding, the state of a bit is determined by the state of the next lower significant bit on the other channel. Resolution of a 7-bit encoder is $2.8125(=360 / 128)$ degrees. A small PC board was constructed and installed near the encoder to provide necessary pull down resistors for the data acquisition I/O inputs.

\section{(c). Reference Signal Generator}

A negative 5-volt reference/trigger voltage is generated with the help of a Philips[7] ECG-3102 photo interrupter module and an opaque Plexiglas slotted wheel. The slotted wheel is connected to the wheel shaft. The photo interrupter module is attached to the frame and consists of a light emitting diode (LED) and a phototransistor. When the slot of the wheel is aligned with the LED and the phototransistor, LED light is received by the phototransistor to generate a negative pulse. Photo interrupter pulse is used to trigger the acquisition of accelerometer signal and is also used as a reference point for the wheel.

\section{(d). Data Acquisition System}

A microcomputer based data acquisition system is used to read the voltages from the instrumentation. System consists of a TDK 486-66 microcomputer, a Data Translation[8] DT2805, low level, 12-bit data acquisition board and ASYST software. DT2805 board has a DT707 screw terminal box which can support thermocouple inputs with a reference junction occupying analog input channel "0". Throughput speed with single channel input is up to $13.7 \mathrm{kHz}$ at $1 \mathrm{X}$ and 10X amplifications. The gains on the board can be set by software for each channel. Major specifications for the board is given in Table 2.

The screw terminal board was previously placed in an aluminum box. The aluminum box provides two 25-pin computer connectors for portability. A female connector is used for digital I/O and a male 25-pin connector is used for rest of the board's functions. The 5 volt voltage from the voltage regulator in the screw terminal box is available on the digital I/O connector and is supplied to the 
machine for the encoder as well as for the photo interrupter circuit (reference signal generator). A relay contact output is available from the analog 25-pin connector.

Table 2. Major Technical Specifications for DT2805 Data Acquisition Board

\begin{tabular}{|c|c|c|c|c|}
\hline $\begin{array}{l}\text { Resolution } \\
\text { ADC/DAC }\end{array}$ & $\begin{array}{l}\text { ADC Channels } \\
\text { (Differential) }\end{array}$ & $\begin{array}{l}\text { \# of DAC } \\
\text { Channels }\end{array}$ & $\begin{array}{l}\text { Programmable } \\
\text { Gains }\end{array}$ & $\begin{array}{l}\text { I/O bits } \\
\text { Port0/Port1 }\end{array}$ \\
\hline $12 / 12$ & 8 & 2 & $1,10,100,500$ & $8 / 8$ \\
\hline
\end{tabular}

To be able to measure the angular position within one degree of resolution, a data acquisition rate of $3600 \mathrm{~Hz}(=360 \mathrm{deg} / \mathrm{rev} * 600 \mathrm{rev} / \mathrm{min} / 60 \mathrm{sec} / \mathrm{min})$ is required. Since two channels are used, required throughput rate of the system has to be at least $7200 \mathrm{~Hz}$. ASYST software is used to acquire two analog signals and two channels of seven bit digital signals that are fed to the board from the wheel balancing machine. One of the analog signals is from the accelerometer filter/amplifier circuit and the other one is from the photo interrupter circuit. Both channels of digital signals are received from the binary encoder. Analog signals are sampled at intervals of $0.14041 \mathrm{msec}[=60 /(593.5 * 360 * 2)]$. This is equivalent to acquiring data every one-degree of revolution of the wheel. Computer acquires accelerometer signal first then it acquires the reference signal half a degree later. Reference signal is used to trigger the start of data acquisition to synchronize the accelerometer signal with the wheel reference point (=angular position at zero degrees).

Only 7 bits out of 8 bits of each I/O port is used for the encoder. The two remaining bits shall be utilized at a later date to switch off the electric motor and apply a magnetic brake to the shaft to stop the wheel. ASYST program reads both channels, 7 bits each, and decodes it into a correct binary number. The binary number is converted to its equivalent decimal value and is displayed as a decimal value and as an angular position in degrees.

After acquiring the data, the computer calculates the mass of the counter weight to be placed on the wheel. Location of the counter weight, with respect to reference signal, is also calculated. The calculated counter weight value and its location are displayed in the DEGREES/OUNCES window on the screen. At this time continuous reading of the wheel reference position, with respect to horizontal plane, is enabled and is displayed in the DEGREES/NUMBER window on the screen. When the wheel is stopped, the operator positions the wheel to the angular value shown in the DEGREES/OUNCES window by rotating it with hand until the indicated angular position in DEGREES/NUMBER window matches the calculated angular position in DEGREES/OUNCES window. The weight is attached to the wheel at the 90 degrees position for easy access. The angular displacement between the 90-degree position of the wheel and the photo interrupter module(reference signal) is incorporated into calculated value of the counter weight position. The screen display of ASYST program for the Wheel Balancing Machine is given in Fig.4. The computer program is not included with this paper due to space limitations. When the word 
"MENU" is typed, the program displays short instructions on how to set up the machine and start the acquisition. In the plot, $\mathrm{x}$-axis is the angular position of the shaft and $\mathrm{y}$-axis is the calculated counterbalance weight to be placed on the rim. The middle window shows how much balancing weight to place on the rim and at what angular position to place it. Upper window shows current angular position of the shaft. Wheel need to be rotated, by hand, to the angular position indicated in the middle window before balancing weight is placed.

\section{CONCLUSIONS}

A dynamic, one plane wheel balancing machine was designed and constructed by the students of ETME 475-Mechanical Systems Design course to satisfy laboratory requirement of the course. Four students worked on the project during last several years. Each time, different aspect of the project was dealt. Project involved mechanical design for the frame, the drive system as well as electronics design for instrumentation.

Although we had some technical problems with the wheel-balancing machine, students liked dealing with and solving these technical difficulties.

Next planned projects are: (a) incorporate automatic starting, stopping, and possibly positioning of the wheel, (b) replace the accelerometer system by force measurement system to improve accuracy, (c) replace the computerized data acquisition system with an on-board micro controller, a digital signal processor, or a microcomputer. Last project will involve both Mechanical and Electrical/Electronics Engineering Technology students.

\section{ACKNOWLEDGMENTS}

Most of this work was done as a requirement for Mechanical Systems Design course at the University of Maryland Eastern Shore, Department of Technology. During last few years, George Bivens, Misheck Mundia, Mark Harewood and Arvind Pastakia worked on the project. Their dedicated work is very much appreciated and acknowledged.

\section{REFERENCES}

1. LabTech/CONTROL, LabTech, 400 Research Drive, Wilmington, MA 01887.

2. ASYST, Data Acquisition, Analysis and Graphics Software. ASYST Software Technologies, Inc., Rochester, New York, 1988.

3. Emin Yilmaz, "Microcomputer Based Instrumentation for Student Designed Wheel Balancing Machine", refereed 1998 ASEE Annual Conference Proceedings, CDROM, Session 1426, paper \#4.

4. PCB Piezotronics, Inc. 3425 Walden Avenue, Depew, NY 14043-2495

5. Burr-Brown, P.O. Box 11400, Tucson, AZ 85734

6. Locheed Martin Librascope, 811 Sonora Avenue, Glendale, CA 91201-2433.

7. Philips ECG Products, P.O. Box 967, 1001 Snapps Ferry Road, Greenville, TN 37744

8. Data Translation, 100 Locke Drive, Marlboro, MA 01752-8528. 


\section{EMIN YILMAZ}

Emin Yilmaz is an Associate Professor of Engineering Technology at the University of Maryland Eastern Shore. He has MS and BS degrees in Mechanical Engineering and a Ph.D. degree from the University of Michigan in Nuclear Engineering. He is a heavy user of both micro and main frame computers in courses and in his research. He developed and taught several laboratory courses in engineering and engineering technology. You may contact him by telephone (410-651-6470) or by e-mail (eyilmaz@umes-bird.umd.edu) for further information. Web Page:

http://www.hawk.umes.edu/eyilmaz. 


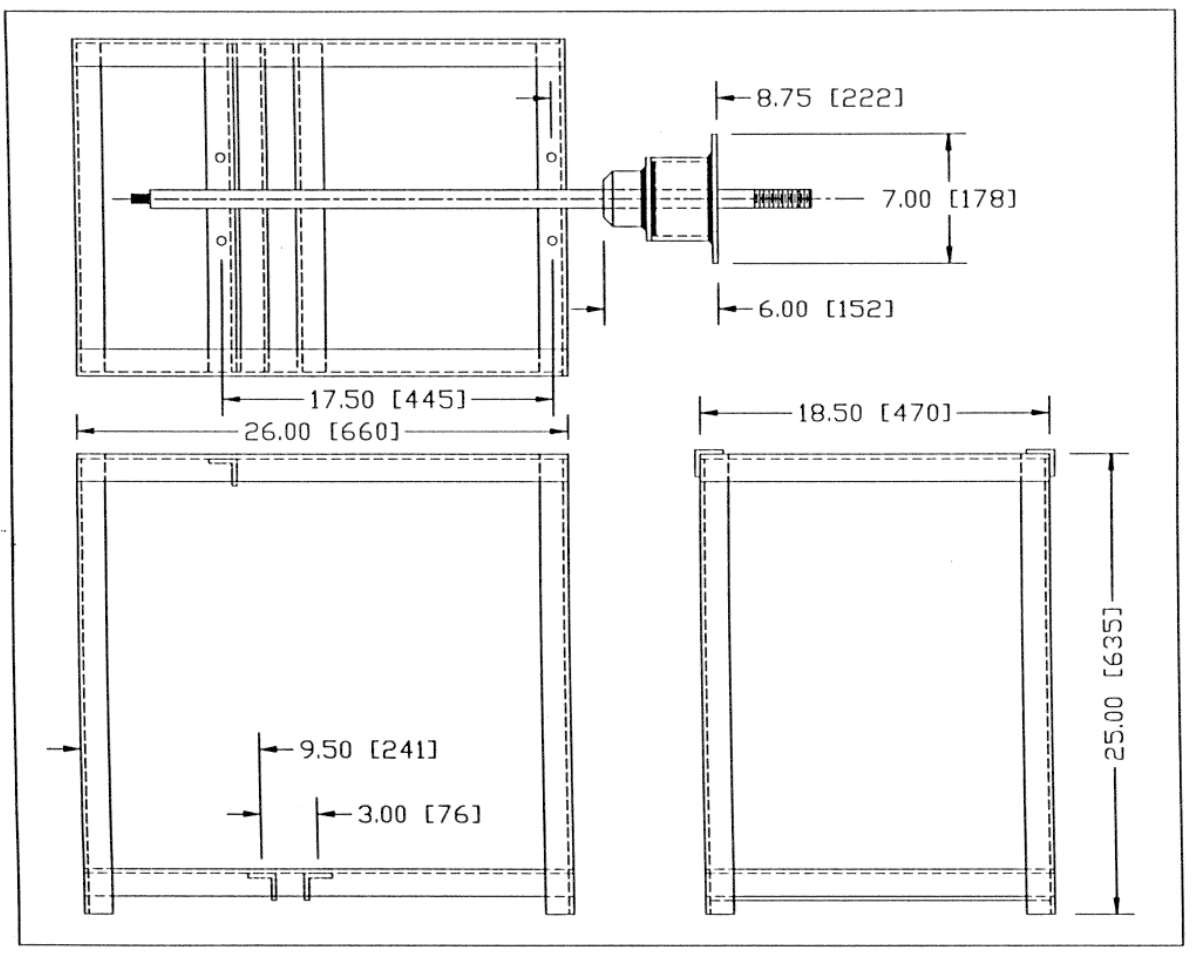

Figure 1. Wheel Balancing Machine Frame.

Shaft and wheel support plate assembly are shown on the top view only. 


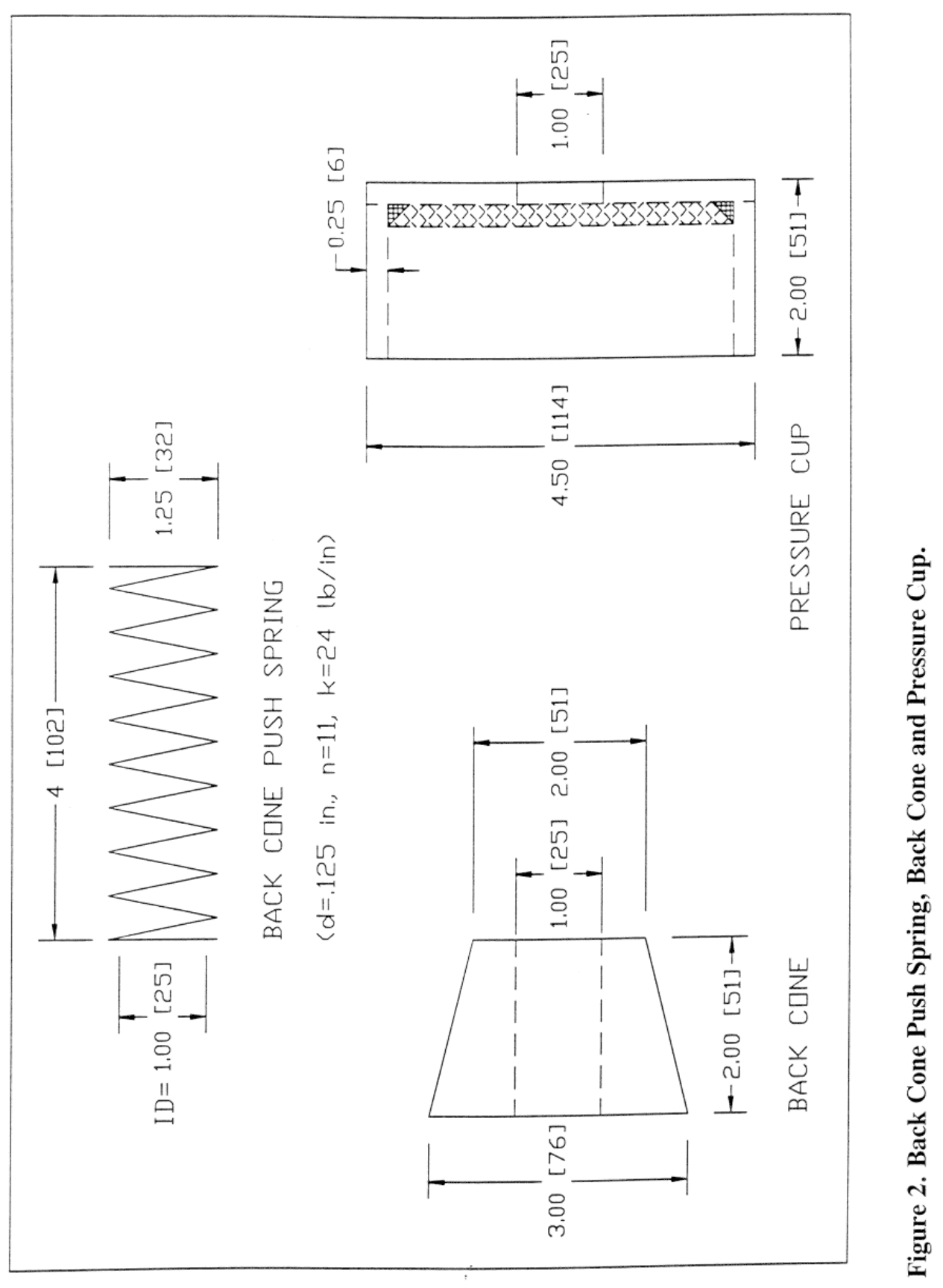

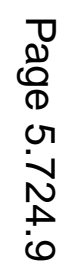




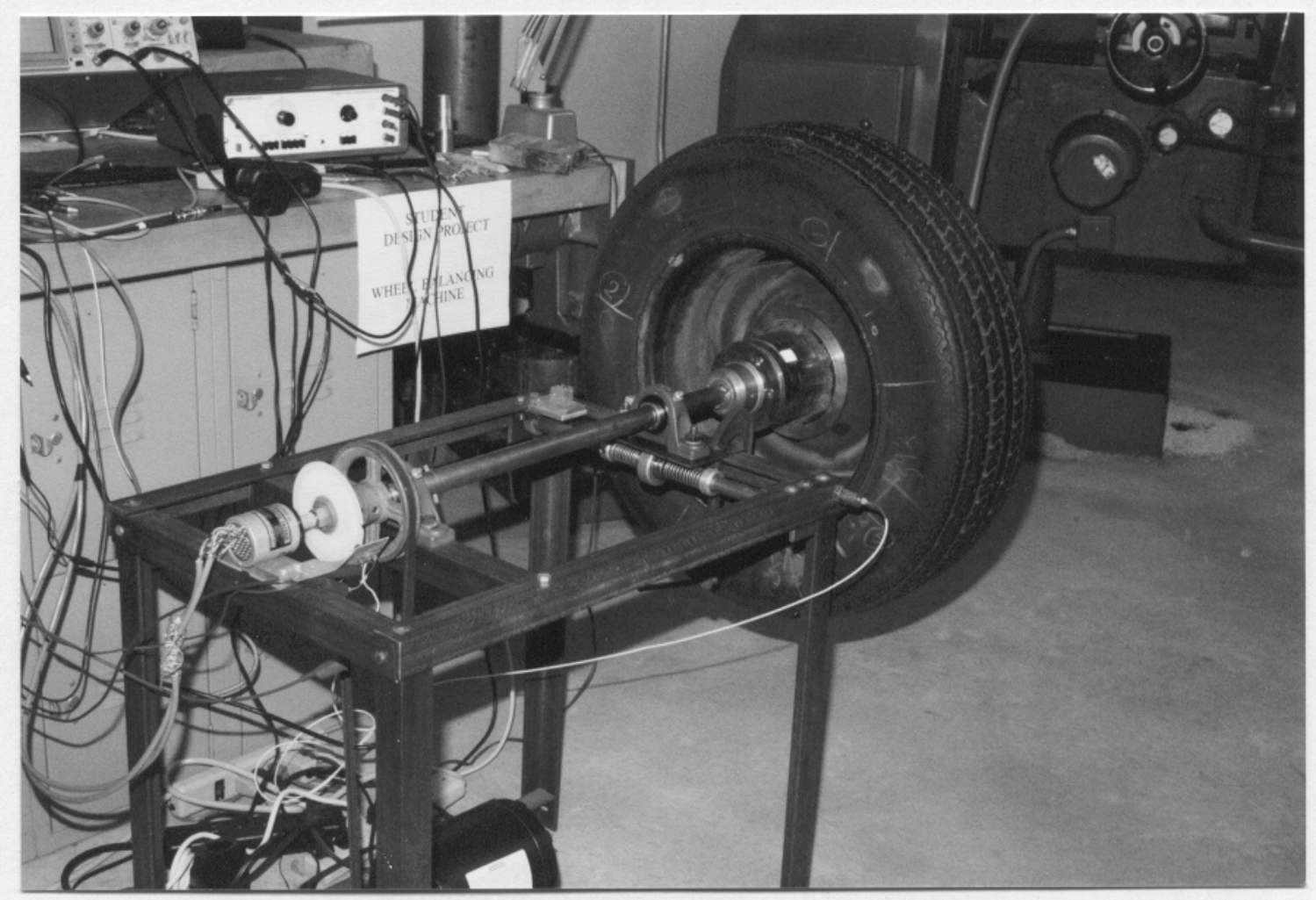

Figure 3. Wheel Balancing Machine. 


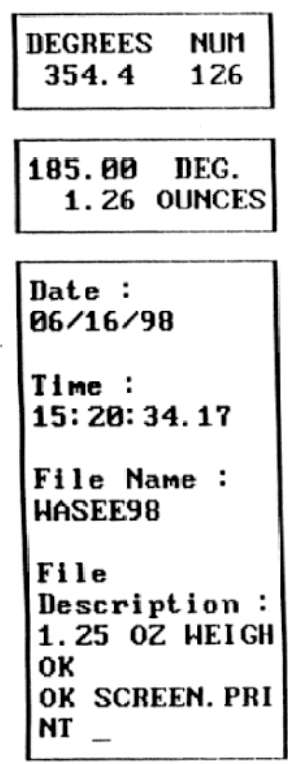

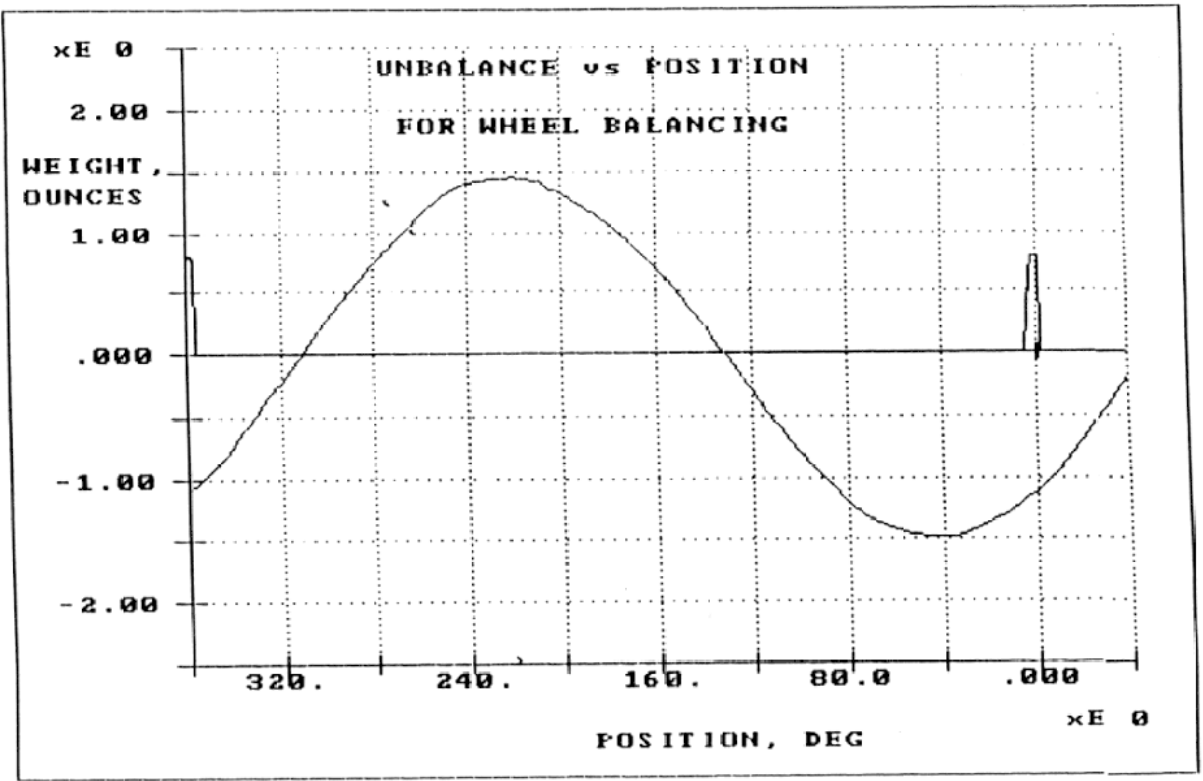

Figure 4. Screen Display of Wheel Balancing Machine ASYST Program. 